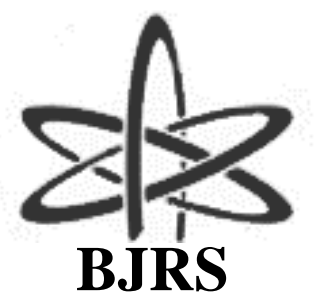

BRAZILIAN JOURNAL

$\mathrm{OF}$

RADIATION SCIENCES

07-01A (2019) 01-16

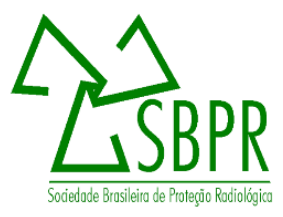

\title{
Análise crítica da legislação federal brasileira para controle de qualidade em radiologia: mamografia
}

\author{
Batista W.O.G., Ribeiro J.C. \\ ${ }^{a}$ Instituto Federal da Bahia, Campus Salvador, Salvador-Bahia-Brasil. \\ wilsonottobatista@gmail.com
}

\section{RESUMO}

Na radiologia, o mamógrafo é um dos equipamentos que, nas ultimas décadas, incorporou maior quantitativo de novos recursos. Dentre esses recursos, seguramente, o mais importante foi à adoção dos receptores digitais. Neste contexto, o objetivo do presente estudo foi avaliar o estado da regulamentação brasileira aplicável ao controle de qualidade em radiologia diagnóstica, mamografia. Foi realizado um estudo comparativo entre quatro documentos, a normativa vigente no Brasil, Portaria no 453 SVS/MS de 01/06/1998 e três protocolos internacionais que foram adotados como referência para o controle de qualidade em mamografia: IAEA HHS no2; OIEA/ARCAL XLIX, Protocol Español de Control de Calidad en Radiodiagnóstico. A análise comparativa desses documentos foi baseada nos aspectos de verificação; periodicidade e tolerância dos testes selecionados Como resultados foram verificados que para sistemas analógicos a regulamentação nacional não contempla em geral 59\% de parâmetros essenciais. As lacunas e deficiências ocorrem por: definições físicas que não se aplicam ao propósito do teste; valores limites e/ou periodicidade aquém do esperado atualmente para o parâmetro avaliado. Conclui-se que apesar do Brasil ser signatário de alguns destes documentos internacionais, a desatualização ou omissão de alguns itens fundamentais para a avaliação da qualidade da imagem, produzem resultados insatisfatórios na obtenção de imagens mamográficas. Por esta razão torna-se urgente a atualização da normativa brasileira para contemplar o estado atual da tecnologia.

Palavras-chave: legislação em radiologia, controle de qualidade, mamografia digital. 


\begin{abstract}
In the radiology field, the mammography equipment is one of the devices that, in the last decades, have incorporated a greater quantity of innovations. Among these innovations, surely, the most important was the adoption of digital receptors. In this context, the objective of the present study was to evaluate the state of the Brazilian regulation applicable to quality control in mammography. A comparative study was carried out between four documents, the current legislation in Brasil, Portaria $n^{\circ} 453$ SVS/MS de 01/06/1998, and three international protocols that were adopted as reference for quality control in mammography: IAEA - HHS no2; OIEA/ARCAL XLIX, Protocol Español de Control de Calidad en Radiodiagnóstico. The comparative analysis of these documents was based on aspects of verification; periodicity and tolerance of the selected tests. As results have been verified that for analogical systems the national legislation does not include in general 59\% of essential parameters. The gaps and deficiencies occur by: physical definitions that do not apply to the purpose of the test; limit values and/or periodicity less than currently expected for the parameter evaluated. It was concluded that, although Brazil is a signatory of some of these international documents, the lack of updating and/or omission of some fundamental items for the evaluation of the image quality, produce unsatisfactory results in obtaining mammographic images. For this reason it is urgent to update the Brazilian legislation to contemplate the current state of technology.
\end{abstract}

Keywords: legislation on radiology, quality control, digital mammography.

\title{
1. INTRODUÇÃO
}

No Brasil o Controle de Qualidade em radiologia diagnóstica, incluindo a mamografia, é regido pela Portaria Ministerial 453/1998 [1] que estabelece as diretrizes básicas de proteção radiológica e de controle de qualidade para a radiologia diagnóstica em medicina e odontologia [1]. Desde 1998 até a presente data, seguramente, a mamografia foi uma das modalidades da radiologia que mais incorporou avanços da tecnologia digital.

Normalmente as normativas de controle de qualidade em radiologia são elaboradas considerando experiências passada e o estado atual da tecnologia. Então é compreensível que normativas como a Portaria Ministerial 453/1998 [1], já apresentem certo grau de defasagem desde o inicio de sua vigência.

Em 2012 o Ministério da Saúde do Brasil publicou a normativa Portaria no 531 GM/MS de 26/03/2012 que institui o Programa Nacional de Qualidade em Mamografia (PNQM) [2]. Em 
2013 o Ministério da Saúde revoga a Portaria no 531 e atualiza o PNQM através da Portaria ${ }^{\circ}$ 2898 GM/MS de 28/11/2013 [3]. Esta normativa é somente a aplicação dos itens constantes da Portaria $n^{\circ} 453$ relativos a mamografia [1], a citada portaria está desatualizada e não contempla a avaliação dos sistemas digitais. Como consequência o PNQM encontra-se igualmente desatualizado.

Neste momento, em 2013, já haviam sido publicados documentos internacionais norteadores para a elaboração e/ou atualização de normativas nacionais nos países da América Latina e Caribe: o Protocolo de Control de Calidad en Radiodiagnóstico: ARCAL XLIX [4] e o Protocolo Control de Calidad en Mamografía [5].

Durante este período de 1998 a 2013 os geradores de raios X foram modernizados incluindo novas combinações alvo/filtro e a introdução de diferentes receptores digitais diretos ou sistemas baseados em placas foto-estimuláveis. Nenhum destes sistemas são comtemplados nas normativas brasileiras $[1,3]$.

Nestas duas ultimas décadas inúmeras iniciativas internacionais foram elaboradas com objetivo central de fornecer base técnica para implementação do controle de qualidade em mamografia analógica e digital. Dentre as iniciativas destacam-se os documentos: protocolos elaborados pela Agencia Internacional de Energia Atômica [6,7] e com igual relevância destacam-se as recomendações da comunidade europeia [8]. Todas estas recomendações internacionais estão validadas e vigentes. Neste contexto o objetivo deste estudo foi analisar criticamente a normativa nacional de controle de qualidade em mamografia quanto a sua adequação e a possível aplicabilidade nos modernos sistemas de mamografia.

\section{MATERIAIS E MÉTODOS}

Foi realizado um estudo comparativo entre quatro documentos, a normativa vigente no Portaria $n^{\circ} 453$ [1] e três protocolos internacionais que foram adotados como referências para o controle de qualidade em mamografia: Protocolos Controle de Qualidade em Mamografia Analógica e Digital do Organismo Internacional de Energia Atômica [6, 7]; os protocolos derivados do projeto ARCAL XLIX e ARCAL/IAEA [4, 6 e o Protocol Español de 
Control de Calidad en Radiodiagnóstico [9]. A análise comparativa desses documentos e sua correlação com a Portaria $n^{\circ} 453$ [1] foi baseada nos aspectos de verificação; periodicidade e tolerância dos testes selecionados.

A análise comparativa foi estruturada considerando os itens pertinentes aos parâmetros geométricos; do gerador e àqueles relacionados ao sistema de recepção de imagem. Esta analise contempla avaliação da periodicidade e os limites de cada item. A estratégia de analise está representada no diagrama, Figura 1 onde localiza a normativa brasileira ao centro e as demais como elementos para comparação e a análise crítica.

Toda a avaliação crítica foi conduzida, considerando as interseções e deficiências presentes na normativa brasileira de controle de qualidade em radiodiagnóstico, quando comparada às normativas e recomendações internacionais.

Também, são apresentados parâmetros associados à avaliação da imagem digital presentes nos outros documentos tais como: razão contraste ruído (RCR); razão sinal ruído (RSR), intensidade média do pixel (VMP). Outra inserção na analise é a dosimetria expressa em termos de dose glandular média $\left(\mathrm{D}_{\mathrm{G}}\right)$.

Figura 1: Diagrama de analise dos protocolos.

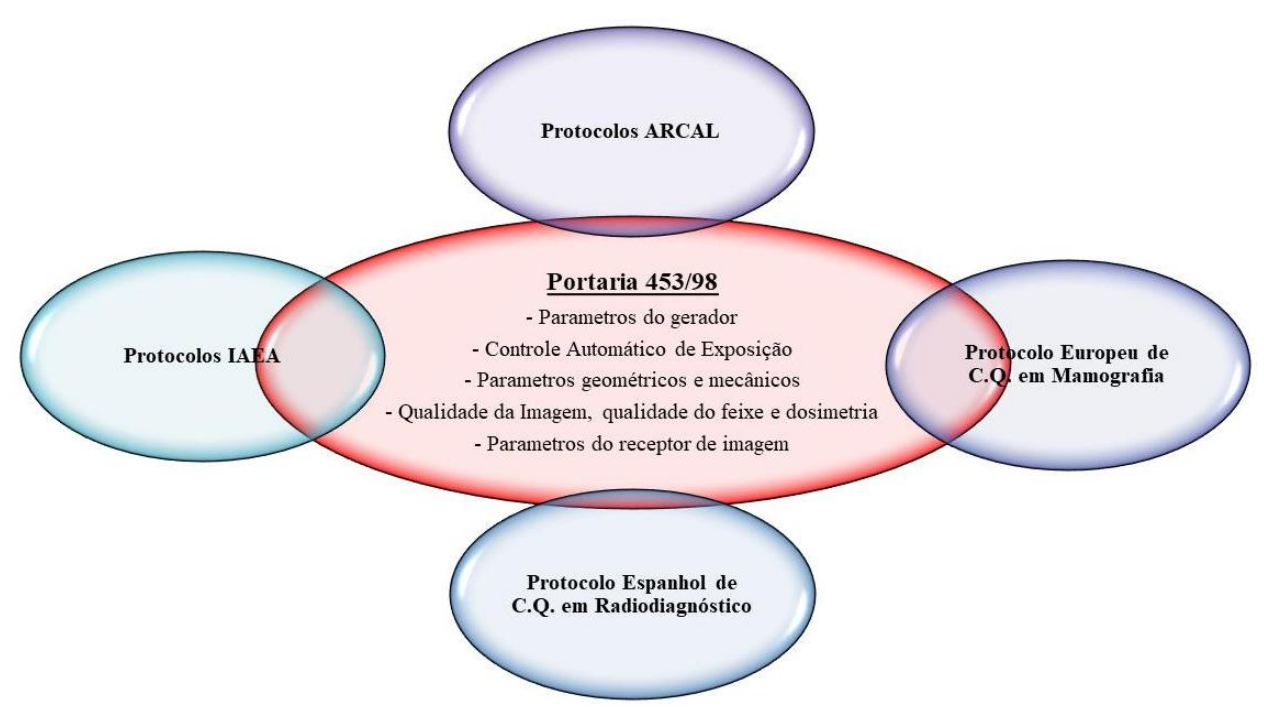




\section{RESULTADOS E DISCUSSÕES}

Os resultados são apresentados de forma estruturada analisando primeiramente aqueles presentes na normativa brasileira e em seguida como na forma que estão definidos e classificados nas demais recomendações e separados por classificação do parâmetro.

\subsection{Parâmetros do gerador}

$\mathrm{Na}$ Tabela 1 estão apresentados os parâmetros associados ao gerador de raios X constantes Portaria $n^{\circ} 453$ [1] e os itens previstos nas recomendações internacionais respectivamente [5, 4, 9]. Conforme previsto Portaria $n^{\circ} 453$ [1] os itens tensão no tubo e tempo de exposição devem atender aos limites apresentados na Tabela 1.

Nota-se claramente que no quesito avaliação das condições de funcionamento do gerador de raios $\mathrm{X}$ a Portaria $\mathrm{n}^{\circ} 453$ [1] apenas requer a verificação de dois parâmetros, $\mathrm{kV}$, e tempo de exposição.

Para avaliar as condições do gerador de raios X nota-se claramente que a portaria 453/98 apenas requer a verificação de dois parâmetros, $\mathrm{kV}$ e tempo de exposição. Quando as recomendações internacionais exigem quatro verificações: $\mathrm{kV}$; tempo de exposição; linearidade, repetitividade e valor do rendimento. Com respeito à periodicidade entre os itens comuns não há diferenças. Contudo quanto às tolerâncias a normativa brasileira apresenta limite de $\pm 10 \%$ enquanto os demais protocolos exigem limites mais restritivos como exatidão $\leq 5 \%$ e repetitividade $\leq 0,5 \mathrm{kV}$ ou $\leq 2 \%$.

Também a Portaria 453/98 [1] não exige a verificação do rendimento do tubo. Esta avaliação é importante por conta do movimento da grade que normalmente é linear. Item que também está vinculado ao tempo de exposição que nos protocolos espanhol [9] e da AIEA [6] diferentemente ao especificado na Portaria 453/98 [1], a tolerância para o tempo está estabelecida em termos de duração da exposição para espessuras de 4,5 cm de poli metil metacrilato (PMMA). 
Tabela 1- Valores de tolerâncias e periodicidade de avaliação dos parâmetros do gerador segundo as recomendações internacionais.

\begin{tabular}{|c|c|c|c|c|c|}
\hline \multirow[b]{2}{*}{ Parâmetro } & \multicolumn{5}{|c|}{ Protocolos } \\
\hline & & $\begin{array}{c}\text { Portaria } n^{\circ} \\
453[1]\end{array}$ & IAEA [6] & ARCAL [4] & SEPR [9] \\
\hline & P: & Anual & $\begin{array}{l}\text { Inicial, semestral e } \\
\text { após alterações }\end{array}$ & $\begin{array}{c}\text { Inicial, anual e após } \\
\text { alterações }\end{array}$ & $\begin{array}{c}\text { Inicial e após } \\
\text { alterações }\end{array}$ \\
\hline $\begin{array}{l}\text { Tensão do } \\
\text { tubo }\end{array}$ & $\mathrm{T}:$ & $\begin{array}{c}\text { Exatidão } \\
\quad \pm 2 \mathrm{kV} \\
\text { Reprodutível } \\
\pm 10 \%\end{array}$ & $\begin{array}{c}\text { Exatidão } \leq 5 \% \\
\text { Repetibilidade }<2 \%\end{array}$ & $\begin{array}{c}\text { Exatidão } \leq \pm 5 \% \\
\text { Repetibilidade } \leq \\
\pm 2 \%\end{array}$ & $\begin{array}{c}\text { Exatidão: Desvio } \\
\quad \leq \pm 1 \mathrm{kV} \\
\text { Repetibilidade } \\
\leq 0,5 \mathrm{kV}\end{array}$ \\
\hline & P: & Anual & Anual & Semestral & $\begin{array}{c}\text { Inicial e após } \\
\text { alterações }\end{array}$ \\
\hline $\begin{array}{l}\text { Tempo de } \\
\text { exposição }\end{array}$ & $\mathrm{T}:$ & $\begin{array}{c}\text { Exatidão } \\
\leq \pm 10 \% \\
\text { Reprodutível } \\
\leq \pm 10 \%\end{array}$ & $\begin{array}{c}\mathrm{t} \leq 1,5 \mathrm{~s} \text { desejável } \\
\mathrm{t} \leq 1,5 \mathrm{~s} \text { aceitável } \\
\text { em espessura de } \\
4,5 \mathrm{~cm}\end{array}$ & $\begin{array}{c}10 \% \text { para } t \geq 200 \mathrm{~ms} \\
15 \% \text { para } \mathrm{t} \leq 200 \mathrm{~ms} \\
\text { Repetibilidade } \\
<10 \%\end{array}$ & $\begin{array}{c}\mathrm{t} \leq 2 \mathrm{~s} \text { para } \\
\text { exposições com } \\
\text { espessura de } 4,5 \mathrm{~cm}\end{array}$ \\
\hline & P: & N/D & Anual & $\begin{array}{c}\text { Inicial e após } \\
\text { alterações }\end{array}$ & $\begin{array}{c}\text { Inicial e após } \\
\text { alterações }\end{array}$ \\
\hline Rendimento & $\mathrm{T}:$ & N/D & $\begin{array}{c}\text { Repetibilidade } \\
<10 \% \\
\text { Linearidade }<10 \%\end{array}$ & $\begin{array}{c}\text { Repetibilidade } \\
<10 \% \\
\text { Linearidade }<10 \%\end{array}$ & $\begin{array}{c}\text { Repetibilidade } \\
<10 \% \\
\text { Coef. Linearidade } \\
<10 \%\end{array}$ \\
\hline $\begin{array}{l}\text { Valor do } \\
\text { rendimento }\end{array}$ & P: & N/D & $\begin{array}{c}\text { Anual } \\
>30 \mu \mathrm{Gy} / \mathrm{mAs} \mathrm{a} \\
1 \mathrm{~m}, 28 \mathrm{kV}, \mathrm{Mo} / \mathrm{Mo}\end{array}$ & $\begin{array}{c}\text { Anual } \\
>30 \mu \mathrm{Gy} / \mathrm{mAs} \text { a } \\
1 \mathrm{~m}, 28 \mathrm{kV}, \mathrm{Mo} / \mathrm{Mo}\end{array}$ & $\begin{array}{c}\text { Anual } \\
>30 \mu \mathrm{Gy} / \mathrm{mAs} \mathrm{a} \\
1 \mathrm{~m}, 28 \mathrm{kV}, \mathrm{Mo} / \mathrm{Mo}\end{array}$ \\
\hline
\end{tabular}

P: periodicidade; T: tolerância: N/D - Não Definido. 


\subsection{Controle Automático de Exposição - CAE}

Para avaliar o CAE, a Portaria $n^{\circ} .453$ [1] exige unicamente o CAE seja reprodutível sob as mesmas condições de exposição, taxa de kerma e com tolerância de 10\%. Desta forma, como definida na citada portaria permite duas interpretações: a primeira remete ao entendimento de que a verificação indicada/exigida é repetitividade e não reprodutibilidade; a segunda conduz o leitor a considerar que como indicado na Portaria $n^{\circ} .453$ [1], todas as verificações exigidas são classificadas como testes de constância e assim o legislador estaria interessado em reprodutividade avaliada a longo prazo.

O correto funcionamento do CAE é essencial para a obtenção de imagens com elevada qualidade independente da espessura e com a menor dose possível. Considerando esta importância, avaliar o CAE, em diferentes condições de exposição é fundamental para assegurar a aquisição de imagens com a qualidade necessária. Por entender assim, os demais protocolos avaliados neste estudo indicam um maior número de verificações, Tabela 2.

A única exigência da Portaria $n^{\circ} .453$ [1] para avaliar se CAE é reprodutível sob as condições definidas na mencionada portaria seguramente não é suficiente para assegurar a capacidade deste importante sistema de controlar os parâmetros de exposição de modo a garantir o mesmo valor de kerma no receptor de imagem e assim assegurando a qualidade da imagem independente da espessura ou densidade da mama examinada. Inclusive porque esta verificação para os modernos geradores e sensores do CAE tende a apresentar uma boa repetitividade. Por esta razão os demais protocolos apresentam uma tolerância mais restritiva de 5\%. Os itens adicionais são de suma importância para garantir a funcionalidade correta do CAE. 
Tabela 2- Itens de avaliação referente ao Controle Automático de Exposição - CAE.

\begin{tabular}{|c|c|c|c|c|c|}
\hline \multirow[b]{2}{*}{ Parâmetro } & \multicolumn{5}{|c|}{ Protocolos } \\
\hline & & $\begin{array}{c}\text { Portaria } n^{\circ} \\
453[1]\end{array}$ & IAEA [6] & ARCAL [4] & SEPR [9] \\
\hline Repetitividade & P: & Anual & Anual. & $\begin{array}{l}\text { Inicial, anual e após } \\
\text { alterações. }\end{array}$ & $\begin{array}{c}\text { Inicial e após } \\
\text { alterações }\end{array}$ \\
\hline do CAE & $\mathrm{T}:$ & $\begin{array}{l}\text { Reprodutível } \\
\quad \pm 10 \%\end{array}$ & $\begin{array}{c}\text { mAs }(\text { kerma }):<5 \% \\
\text { DO } \leq 0.1\end{array}$ & $\begin{array}{c}\text { Repetibilidade } \leq \pm \\
2 \%\end{array}$ & $\begin{array}{c}\mathrm{D}_{\mathrm{G}}: \leq 5 \% \\
\mathrm{SNR} \leq 5 \%\end{array}$ \\
\hline Incremento da & P: & N/D & Anual. & Anual. & N/D \\
\hline $\begin{array}{l}\text { óptica por } \\
\text { passo do } \\
\text { seletor }\end{array}$ & $\mathrm{T}$ : & N/D & $\begin{array}{c}\mathrm{DO}=0,1 \text { à } 0,2 \\
\text { mAs: } 12 \% \text { à } 15 \%\end{array}$ & $\mathrm{DO}=0,1$ a 0,2 & N/D \\
\hline \multirow{2}{*}{ Ajuste do CAE } & P: & N/D & Anual & N/D & $\begin{array}{c}\text { Inicial e após } \\
\text { alterações }\end{array}$ \\
\hline & $\mathrm{T}:$ & N/D & $\begin{array}{c}\mathrm{D}_{\mathrm{G}}<2,5 \mathrm{mGy} \text { para } \\
4,5 \mathrm{~cm}\end{array}$ & N/D & $\begin{array}{c}\mathrm{D}_{\mathrm{G}}<2,5 \mathrm{mGy} \text { para } \\
4,5 \mathrm{~cm}\end{array}$ \\
\hline $\begin{array}{c}\text { Compensação } \\
\text { para }(\mathrm{kV}\end{array}$ & P: & N/D & $\begin{array}{l}\text { Inicial, anual e após } \\
\text { alterações. }\end{array}$ & $\begin{array}{c}\text { Inicial, anual e após } \\
\text { alterações. }\end{array}$ & $\begin{array}{c}\text { Inicial, anual e após } \\
\text { alterações. }\end{array}$ \\
\hline $\begin{array}{l}\text { espessuras e } \\
\text { modo) }\end{array}$ & $\mathrm{T}:$ & N/D & $\begin{array}{l}\mathrm{DO} \leq \pm 0,15 * \\
\mathrm{CNR} \leq 103 \%\end{array}$ & $\mathrm{DO} \leq \pm 0,15^{*}$ & $\begin{array}{c}\mathrm{DO} \leq \pm 0,15 * \\
\mathrm{CNR} \leq 103 \%\end{array}$ \\
\hline & P: & N/D & Semanal & N/D & Semanal. \\
\hline $\begin{array}{c}\text { do CAE } \\
\text { para } 4,5 \mathrm{~cm} \mathrm{de} \\
\text { PMMA }\end{array}$ & $\mathrm{T}$ : & N/D & $\begin{array}{c}\mathrm{DO} \leq 0,15 \\
\mathrm{VMP} \\
\leq \pm 10 \% \\
\mathrm{RSR} \leq \pm 10 \%\end{array}$ & $\mathrm{~N} / \mathrm{D}$ & $\begin{aligned} \mathrm{DO} & \leq 0,15 \\
\mathrm{VMP} & \leq \pm 10 \% \\
\mathrm{RSR} & \leq \pm 10 \%\end{aligned}$ \\
\hline $\begin{array}{r}\text { P: periodicidad } \\
\text { Ruído; RCR - Raz } \\
\text { DO - Densidade Ó }\end{array}$ & & $\begin{array}{l}\text { : tolerância: N/D } \\
\text { Contraste Ruído; } \\
\text { a. * - tolerância r }\end{array}$ & $\begin{array}{l}\text { - Não Definido; DG - } \\
\text { VMP - Valor Médio do } \mathrm{F} \\
\text { elativa ao valor da DO ob }\end{array}$ & $\begin{array}{l}\text { Dose Glandular Média; } \\
\text { Pixel (intensidade média d } \\
\text { tido para } 4,5 \mathrm{~cm} \text {. }\end{array}$ & $\begin{array}{l}\text { RCR - Razão Contraste } \\
\text { o tom de cinza no pixel); }\end{array}$ \\
\hline
\end{tabular}




\subsection{Parâmetros geométricos e mecânicos}

A normativa brasileira [1] prevê avaliação do valor da força de compressão e a coincidência do campo de radiação com receptor de imagem. A coincidência deve atender ao limite de $\pm 2 \%$ da distancia foco receptor de imagem. Este é o mesmo limite adotado para radiologia convencional. Contudo para mamografia é importante que seja exigido à cobertura total do receptor de imagem permitindo diferenças de até $\pm 5,0 \mathrm{~mm}$ em todas as bordas exceto na borda da parede torácica $[4,5,6.9]$. Para esta borda a coincidência deve ser exata ou uma invasão ou perda da parede torácica de máximo: $\pm 3,0 \mathrm{~mm}[4] ; \pm 5,0 \mathrm{~mm}[6,9]$ e perda de tecido $<5,0 \mathrm{~mm}$. Como podemos observar os outros protocolos envolvidos na presente comparação, Tabela 3, exigem limites explícitos e também mais restritivos.

Com relação ao sistema de compressão os protocolos da AIEA [5, 6], ARCAL [4] e SEPR [9] recomendam a avaliação da espessura comprimida. Esta é uma avaliação muito importante, pois, inúmeros mamógrafos necessitam reconhecer a espessura comprimida para selecionar os fatores de exposição no CAE. A normativa brasileira não prevê esta avaliação.

\subsection{Qualidade da imagem, qualidade do feixe e dosimetria}

\subsubsection{Qualidade da imagem}

Segundo a portaria ministerial 453/98 no Brasil deve-se avaliar a qualidade da imagem em mamografia apenas com o uso de um simulador minimamente equivalente ao adotado como padrão pelo Colégio Americano de Radiologia - ACR, com periodicidade mensal.

De fato esta é uma importante verificação porem, a periodicidade mensal é demasiadamente extensa. Observa-se que nas normativas AIEA [5, 6] e SEPR [9], Tabela 4, a periodicidade desta verificação é semanal. 
Tabela 3 - Parâmetros geométricos e mecânicos relacionados ao Sistema de colimação e compressão da mama.

\begin{tabular}{|c|c|c|c|c|c|}
\hline \multirow[b]{2}{*}{ Parâmetro } & \multicolumn{5}{|c|}{ Protocolos } \\
\hline & & $\begin{array}{c}\text { Portaria }^{0} \\
453[1]\end{array}$ & IAEA [6] & ARCAL [4] & SEPR [9] \\
\hline Alinhamento e & P: & Anual & $\begin{array}{l}\text { Inicial, semestral e } \\
\text { após alterações. }\end{array}$ & $\begin{array}{l}\text { Inicial, anual e após } \\
\text { alterações. }\end{array}$ & $\begin{array}{c}\text { Inicial, anual e após } \\
\text { alterações. }\end{array}$ \\
\hline $\begin{array}{l}\text { exatidão da } \\
\text { colimação }\end{array}$ & $\mathrm{T}$ : & $\begin{array}{l}<2 \% \text { da } \\
\text { DFR }\end{array}$ & $\begin{array}{c}\text { Exatidão } \leq 2 \% \\
\text { Exatidão } \leq+5 \mathrm{~mm} \\
\text { (parede torácica) }\end{array}$ & $\begin{array}{c}\text { Exatidão } \leq \pm 5 \mathrm{~mm} \\
\text { Exatidão } \leq \pm 3 \mathrm{~mm} \\
\text { (parede torácica) }\end{array}$ & $\begin{array}{c}\text { Exatidão } \leq 2 \% \\
\text { Exatidão } \leq+5 \mathrm{~mm} \\
\text { (parede torácica) }\end{array}$ \\
\hline $\begin{array}{c}\text { Exatidão da } \\
\text { espessura }\end{array}$ & P: & N/D & $\begin{array}{l}\text { Inicial, anual e após } \\
\text { alterações. }\end{array}$ & $\begin{array}{l}\text { Inicial, anual e após } \\
\text { alterações. }\end{array}$ & $\begin{array}{c}\text { Inicial, anual e após } \\
\text { alterações. }\end{array}$ \\
\hline comprimida & $\mathrm{T}:$ & $\mathrm{N} / \mathrm{D}$ & Exatidão $\leq+5 \mathrm{~mm}$ & Exatidão $\leq+5 \mathrm{~mm}$ & Exatidão $\leq+5 \mathrm{~mm}$ \\
\hline
\end{tabular}

Em qualquer tipo de receptor de imagem a avaliação da resolução espacial é um parâmetro extremamente importante. Especificamente para uma modalidade de radiodiagnóstico, como a mamografia, que deve ser capaz de detecção de pequenos detalhes esta avaliação é necessária e importante. Assim nota-se que a normativa brasileira [1,3] deixa uma lacuna importante quando não prevê a verificação da resolução espacial principalmente para os receptores digitais.

\subsubsection{Qualidade do feixe}

A avaliação da qualidade do feixe é expressa em termos de camada semi-reddutora (CSR). $\mathrm{Na}$ normativa brasileira está definida apenas para combinação alvo/filtro (Mo/Mo) e como intervalo aceitável de: kV/100 $\pm 0,1 \mathrm{~mm}$ de Al. Contudo, nos dias atuais há inúmeras outras combinações de alvo/filtro disponíveis nos mamógrafos. Nota-se a ausência do estabelecimento de valores para as diferentes combinações. 


\subsubsection{Dosimetria}

Na portaria ministerial 453/98 [1] a avaliação dosimétrica em mamografia está definida em termos de kerma no ar na superfície da pele de uma mama comprimida de espessura igual a $4,5 \mathrm{~cm}$. O valor do nível de referencia em diagnostico de $10 \mathrm{mGy}$ é definido como valor a ser adotado nas avaliações dosimétricas.

Protocolos modernos [6, 7,9] definem como parâmetro dosimétrico a dose glandular média para varias espessuras e adotam a espessura de $4,5 \mathrm{~cm}$, equivalente a uma mama comprimida com 5,3 cm de espessura com 50\% de tecido glandular e 50\% de tecido adiposo, para ser adotado em verificações dosimétricas rotineiras.

A especificação em termos de dose glandular média $\left(D_{G}\right)$ é importante pelo fato de que este parâmetro reflete o valor médio da dose absorvida no tecido glandular. Enquanto que o valor do kerma incidente caracteriza o feixe de radiação e não a dose absorvida nos tecidos, em particular o tecido glandular mamário.

\subsubsection{Receptor de imagem}

Para os receptores do tipo tela-filme a portaria 453/98 e o programa de qualidade em mamografia (PNQM) [1, 3] determinam a avaliação sensitométrica com periodicidade semanal. Para os receptores digitais e sistemas foto-estimuláveis (sistemas de radiografia computadorizada) não há definição de avaliação e/ou critérios de aceitação pois a norma não contempla estas tecnologias. Desta forma, a normativa brasileira e o programa de qualidade em mamografia $(\mathrm{PNQM})[1,3]$ apresentam inúmeras deficiências no tocante à avaliação de sistemas receptores de imagem com tecnologia digital. 
Tabela 4 - Parâmetros de verificação associados à qualidade da imagem, qualidade do feixe e dosimetria.

\section{Protocolos}

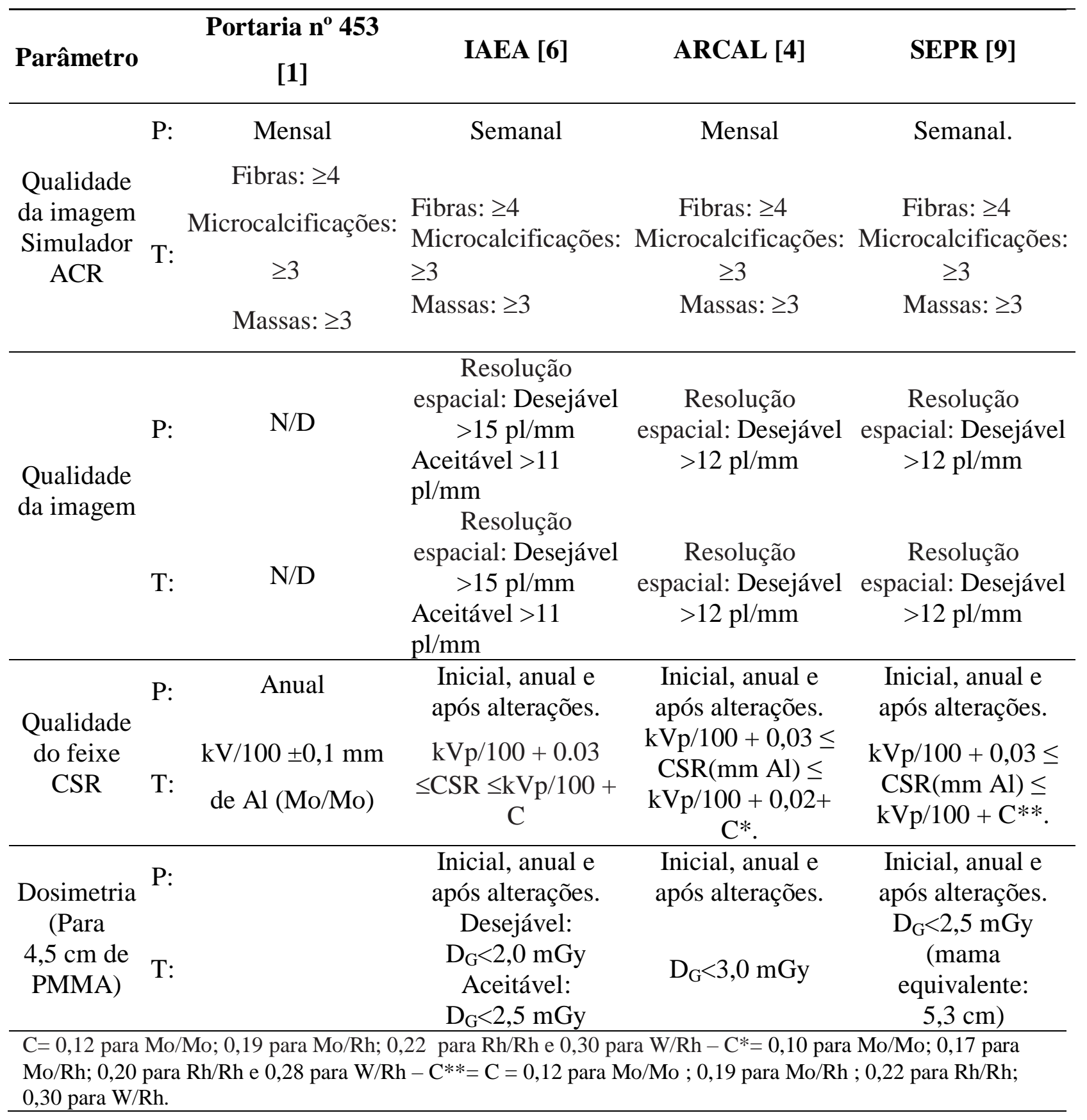

Nos receptores digitais, incluindo os sistemas de radiografia computadorizada (sistema CR) há a necessidade de avaliação de um conjunto mínimo de parâmetros essenciais que são: Razão 
Contraste Ruído (CNR); Razão Sinal Ruído (SNR); uniformidade do detector e resposta do detector. Também, e mais critico para os sistemas CR, é importante a avaliação de presença de artefatos e imagem residual.

\subsection{Considerações gerais}

É notável o grau de desatualização da normativa brasileira [1] nos itens pertinentes ao controle de qualidade em mamografia. Mais critico é o programa nacional de qualidade em mamografia (PNQM) datado de 2013 [3] data posterior à existência de documentos mais atualizados que inclusive aqueles que o Brasil é signatário. Desta forma não é compreensível à manutenção de uma normativa, por 20 anos sem atualização e que não contempla o nível tecnológico em que se encontra os equipamentos de mamografia no País.

Vale ressaltar que neste interstício de 1998 a 2013 houve uma iniciativa que culminou com a elaboração de um manual, entenda-se um protocolo técnico de controle de qualidade em radiologia, intitulado Radiodiagnóstico Médico: Desempenho de Equipamentos e Segurança [10] que comtempla a mamografia. Contudo este manual estabelece tolerâncias, definições e metodologia para obtenção de resultados que difere daqueles estabelecidos na Portaria $\mathrm{n}^{\circ} 453$ [1]. Desta forma, mesmo este documento tenha origem na Agencia Nacional de Vigilância Sanitária (ANVISA) nos parece que não se sobrepõe a uma portaria federal em vigor.

Para que uma normativa não alcance elevado grau de desatualização é importante adotar uma estratégia de redação que seja adequada e flexível à evolução tecnológica. Para que uma normativa não caduque rapidamente é importante fixar-se na avaliação dos parâmetros de qualidade, dosimetria e segurança que sejam indispensáveis à técnica de mamografia evitando a apresentação de periodicidade, tolerâncias e limites de aceitação na forma numérica.

Como alternativa, pode-se adotar as recomendações internacionais e/ou utilizar as normativas em que o Brasil seja signatário, para efetivar um programa de controle de qualidade que de fato assegure a realização de exames com qualidade aceitável e compatível com a tecnologia presente. 


\section{CONCLUSÃO}

Considerando as particularidades e especificidades da imagem mamográfica conclui-se que é urgente a atualização da normativa brasileira destinada ao controle de qualidade em mamografia para atualizar inúmeros critérios e tolerâncias assim como contemplar a tecnologia digital presente nos receptores de imagem. Conclui-se também, que a atualização necessária deve contemplar os modernos geradores; as diferentes combinações alvo/filtro; os receptores digitais; a avalição da qualidade da imagem segundo os parâmetros básicos já estabelecidos e que seja redigida com previsão de revisão periódica de acordo com o avanço da tecnologia e do conhecimento técnico-cientifico.

\section{AGRADECIMENTO}

Os autores agradecem ao IFBA - Instituto Federal da Bahia e a FAPESB - Fundação de Amparo a Pesquisa do Estado da Bahia pelo apoio aos trabalhos desenvolvidos nesta linha de pesquisa.

\section{REFERÊNCIAS}

[1] BRASIL. Portaria n ${ }^{\circ}$ 453/GM/MS, de 01 de junho de 1998. Aprova o Regulamento Técnico que estabelece as diretrizes básicas de proteção radiológica em radiodiagnóstico médico e odontológico. Brasilía, DF: Diário Oficial da União.

[2] BRASIL. Portaria n ${ }^{\circ}$ 531/GM/MS, de 26 de março de 2012. Institui o Programa Nacional em Mamografia. Brasilía, DF: Diário Oficial da União, 26 mar. 2012. n. 60, Seção 1, p.91.

[3] BRASIL.Portaria $n^{\circ}$ 2898/GM/MS, de 28 de novembro de 2013. Atualiza o Programa Nacional de Qualidade em Mamografia (PNQM/MS). Brasília DF: Diário Oficial da União. Seção 1, fl.119-21 (2013 nov 29); 2013 
[4] IAEA - International Atomic Energy Agency, Acuerdo Regional de Cooperaçión para la promocion de la ciencia y tecnología nuclear em Latino América y el Caribe. Protocolos de Control de Calidad en Radiodiagnóstico: IAEA/ARCAL XLIX. Viena, 2001.

[5] IAEA - International Atomic Energy Agency, Control de Calidad en Mamografia, Protocolo elaborado en el marco de dos proyetos regionals ARCAL/IAEA, TECDOC-1517, Vienna, 2006.

[6] IAEA - International Atomic Energy Agency, Quality assurance programme for screen film mammography. Human health series No. 2. Vienna. 2009.

[7] IAEA - International Atomic Energy Agency, Quality assurance programme for digital mammography. Human health series No. 17. Vienna, 2011.

[8] Perry N, Broeders M, de Wolf C, et al. European guidelines for quality assurance in breast cancer screening and diagnosis. 4th ed. Luxembourg: European Communities, 2006.

[9] SEFM-SEPR-SERAM, 2012. Protocolo Español de Control de Calidad en Radiodiagnóstico, 1st ed. Senda Editorial, S.A, Madrid.

[10] BRASIL. Ministério da Saúde. Agência Nacional de Vigilância Sanitária. Radiodiagnóstico Médico: Desempenho de Equipamentos e Segurança/Ministério da Saúde, Agência Nacional de Vigilância Sanitária. - Brasília: Ministério da Saúde, 2005. 